\title{
Key Risks and Development Strategies for China's High-End Medical Equipment Innovations
}

\author{
Zhihui Zhang',2 \\ Wei Rao (iD) ${ }^{3-5}$ \\ 'Post-Doctoral Research Station, China \\ Three Gorges Corporation, Beijing, \\ 100038, People's Republic of China; ${ }^{2}$ The \\ Institute for the History of Natural \\ Sciences, Chinese Academy of Sciences, \\ Beijing, I00190, People Republic of \\ China; ${ }^{3}$ Technical Institute of Physics and \\ Chemistry, Chinese Academy of Sciences, \\ Beijing, I00190, People's Republic of \\ China; ${ }^{4}$ Beijing Key Laboratory of \\ CryoBiomedical Engineering, Beijing, \\ I00190, People's Republic of China; \\ ${ }^{5}$ School of Future Technology, University \\ of Chinese Academy of Sciences, Beijing, \\ I0I408, People's Republic of China
}

\begin{abstract}
Objective: Sufficient amounts of basic medical materials and high-end medical equipment are required for epidemics. This study aims to investigate and determine the key risks and main factors influencing China's high-end medical equipment innovations using a SWOT (Strengths, Weaknesses, Opportunities, Threats) matrix. Then, on the basis of findings and relevant literature concerning the development of China's high-end medical equipment in recent years, especially during the COVID-19 period, we put forward strategies for the development of and innovations in high-end medical equipment for China, based on an analytic network process ANP-SWOT model.
\end{abstract}

Methods: In this study, a comprehensive ANP-SWOT analysis model was selected to examine the current state of development of the high-end medical equipment innovation industry in China. First, a SWOT model was used to comprehensively analyze the internal and external factors influencing the development of the industry. Then, an ANP network structure was designed to accurately reflect the relationships among the influencing factors. Subsequently, weights for the influencing factors were determined according to the importance of the factors, and alternative choices for China's strategy for high-end medical equipment innovation were presented.

Results: The results revealed that the essential features of the best strategy for the innovation and development of China's high-end medical equipment industry were as follows: first, speeding up the construction and improvement of a technological innovation system that is enterprise-dominated, market-oriented, and involves joint industry-university research; second, a greater focus on increasing the financial support for research and development and industrialization; and third, strong government support through taxes, medical insurance, promotion of talent, and appropriate land usage.

Conclusion: Strong governmental support through taxes, medical insurance, promotion of talent, and land usage is required to ensure rapid development of the high-end medical equipment industry in China.

Keywords: ANP-SWOT model, high-end medical equipment, innovation, risk, policies

\section{Introduction}

China's medical equipment market has developed rapidly in recent years. The average annual growth rate has been estimated at approximately $15 \%$, which is far higher than the international growth rate of 5\%. ${ }^{1}$ According to the 2020 China Medical Equipment Green Book, by the end of 2019, there were 18,000 industrial production enterprises and the market scale had reached 800 billion yuan, compared with 214.8 billion yuan in 2010. However, at the same time, the outbreak of COVID-19 has brought about new opportunities for the innovative development
Technical Institute of Physics and

Chemistry, Chinese Academy of Sciences

29 Zhongguancun East Road, Haidian

District, Beijing, I00190, People's

Republic of China

$\mathrm{Tel}+86-10-82543719$

Fax +86-10-82543766

Email weirao@mail.ipc.ac.cn 
and export of medical apparatus and instruments. In 2020, China's total exports of medical apparatus and instruments reached 28.702 billion US dollars, with a year-on-year growth of $21.46 \%$. In addition, the proportion of highend products in China's export of medical apparatus and instruments increased, the quality and benefit of products have been improved continuously, which has better adapted to the demands and complex changes of international market, and has withstood the test of increasing trade friction. ${ }^{2}$

Public health crises represent a severe test for national public health crisis governance. ${ }^{3}$ However, recently, weaknesses in China's high-end medical equipment industry have been exposed. It has become evident during the COVID-19 epidemic that elderly people with weak immune systems are susceptible and high-risk groups, ${ }^{4}$ and the need for high-end medical equipment to assist such people has been highlighted. With the intensified restraints that the United States has placed on China, the high-end medical equipment industry in China has faced greater challenges in relation to science and technology. ${ }^{5}$ Therefore, when inspecting the scientific research for the prevention and control of COVID-19 in Beijing on March 2, 2020, President Xi Jinping pointed out that

we should accelerate the improvement of the weak links of China's high-end medical equipment; speed up the tackling of problems in key technologies; and break through the bottleneck of technology and equipment in order to realize the autonomous and controllable development of high-end medical equipment.

These basic tasks have clear objectives and will have profound impacts on the development of the high-end medical equipment industry in China. However, in-depth research on the risks of and solutions for industry development remains lacking.

In the existing research, there is insufficient in-depth and systematic analysis on this important topic. It is urgent to understand the core problems affecting China's highend medical equipment innovation and their root causes based on a clear analytic model. In addition, it is essential to seek effective solutions for enhancing the competitiveness of China's high-end medical equipment as soon as possible.

In a SWOT analysis, $\mathrm{S}$ indicates strength, $\mathrm{W}$ stands for weakness, O denotes opportunity; and T indicates threats. ${ }^{6}$ Since SWOT analysis was developed in the 1950s, it has been widely used as a method to comprehensively analyze the internal and external environments influencing various research topics. We adopt a SWOT analysis in the present study to achieve a comprehensive, systematic, and accurate analysis of the research situation. We supplement the SWOT analysis with an analytic network process (ANP), which is an extension of analytic hierarchy process and is used to solve situations in which the structures of decision problems exhibit dependence and feedback relationships. On the basis of the results of the ANP-SWOT model, we examine the key risks and development strategies for China's high-end medical equipment innovations, and put forward relevant policy suggestions.

This paper conducts a SWOT analysis of China's highend medical equipment innovations. Then, we undertake a strategic analysis of the innovation and development of China's high-end medical equipment based on an ANPSWOT model, including the SWOT matrix analysis, and provide step-by-step policy recommendations.

\section{SWOT Analysis of China's High-End Medical Equipment Innovations Development Strengths of High-End Medical Equipment Innovations in China}

(S)

(1) Developing its high-end medical equipment industry and focusing on related key technologies through a national system would be of significant advantage to China. As an example, we consider extracorporeal membrane oxygenation (ECMO) equipment (commonly known as artificial lungs), which can play a significant role in the treatment of critically ill and respiratory patients. The demand for this high-end medical equipment has soared during the COVID-19 epidemic. However, the development of this type of technology began relatively late in China. Prior to the epidemic, China had accumulated ECMO technology and developed some equipments. For example, Shandong Magnetic Bearing Engineering Technology Research Center spent more than 10 years developing its ECMO prototype and had completed departmental in-vitro experiments. ${ }^{2}$ However, there was a lack of proprietary branding and core technology. During the epidemic, China made a rapid breakthrough in the development of ECMO by virtue of the coordination abilities of its national socialist system.

(2) Influential industry giants in China seized the window provided by the epidemic and rapidly increased the market shares of their products. For example, Mindray has 
become China's largest and the world's leading supplier of medical apparatus, instruments, and solutions. During the epidemic, the market share of the company's respirators successfully surpassed that of imported brands and it became the top supplier in China during the first half of 2020 through the realization of high-end medical equipment innovations. In addition, as the largest manufacturer of oxygen generators and respirators in China, Yuwell has benefited from increased demands during the epidemic.

(3) Government departments attach great importance to and strongly promote the integration of medicine with engineering. Recently, the People's Republic of China (PRC) has actively built public service platforms to continuously improve the research capacities of highend medical equipment through technical support and industry services. It did so under the guidance of the National Health Commission, the National Development and Reform Commission, the Stateowned Assets Supervision and Administration Commission of the State Council, other ministries and commissions of the PRC, along with the basic public service platform for industrial technology under the Ministry of Industry and Information Technology of China and the Instrumentation Technology and Economy Institute. In addition, the industrialization of high-end medical equipment and the construction and applications of big data service platforms have been actively promoted to achieve resource aggregation and sharing. In this regard, the Ministry of Industry and Information Technology and the China Association of Medical Equipment jointly released the manual "Medical Equipment and Key Parts and High-end Medical Equipment Industrialization and Applications of Big Data Service Platforms".

(4) China's main investors in high-end medical equipment are greatly diversified, and many large private enterprises are now involved. We found that as a result of policy support and a larger number of high-end medical equipment companies investing in science and technology innovation, the main investors in the medical equipment industry have become more diversified. The investors include not only medical device companies, but also large pharmaceutical companies, such as Sinopharm and Jointown Pharmaceutical Group; Internet companies, including Alibaba, Tencent, and Baidu; and advanced manufacturing enterprises, including Midea, Gree, and Haier, which have manufactured various types of medical equipment.

\section{Weaknesses of High-End Medical Equipment Innovations in China (W)}

The Development of Medical Apparatus and Instruments Commenced Late in China, and the Domestic Market Was Monopolized by Multinational Companies China's high-end medical device market has long been monopolized by foreign enterprises. The monopolization by big brands owned by foreign-funded enterprises has not only led to high prices for medical equipment and services, but has also resulted in serious patent barriers. Moreover, there are major risks that the daily data on physical examinations and diagnostic imaging of Chinese people will be disclosed to other countries. ${ }^{8}$ Due to the complexity of highend medical equipment technology, major investments in research and development (R\&D), and replacement difficulties, ${ }^{9}$ China's high-end medical industry started late and it continues to lag behind multinational companies.

Objectively speaking, a major gap exists between foreign and Chinese high-end medical equipment enterprises in regard to product quality, scale, and efficiency. According to the China Association of Medical Equipment, seven of the top 10 enterprises in China are multinational enterprises. In 2020, the China Association of Medical Equipment issued "Notice on the Recommendation of Urgently Needed Medical Equipment for COVID-19 Outbreak Control" five times in succession. In relation to respirators, defibrillators, and medical imaging, the proportion of foreign enterprises recommended as suppliers in the list was relatively high. ${ }^{10}$ The scale of China's market for respirators is gradually increasing, but the market share of locally made respirators remains low. In addition, the strategic supplies of ventilators are considered to be insufficient. Further, it is revealing that only one of the seven ECMO suppliers is a Chinese enterprise, indicating that the monopoly of emergency equipment by multinational enterprises has not completely changed. ${ }^{11}$ It has proven difficult for China's domestic high-end medical equipment industry to enter the government procurement list, and the procurement gates of a Grade III Level A hospitals.

\section{A Shortage of Core Technology and Components for High-End Medical}

\section{Equipment}

Medical equipment provides weapons to fight illness and protection for medical staff, who are in the first line of 
defense during an epidemic. During the fight against the epidemic in 2020, China's domestic first-aid equipment, respirators, in-vitro diagnostic equipment, and other highend medical devices were mainly in short supply when urgently needed. The situation was characterized by weak technology development, inadequate reserves, low production capacities, and shortages of key parts. There were major problems related to domestic respirators, in that both domestic noninvasive and invasive respirators were dependent on the import of key parts for production. The majority of domestic respirator manufacturers in China are mid-stream manufacturers of main frame respirators, for which the main raw materials and key parts, such as turbo compressors, sensors, and chips, are imported from Switzerland, the United States, Japan, and Germany. This dependence on imported components negatively affected China's ability to rapidly increase respirator production.

Domestic high-end medical device producers have experienced shortcomings in terms of support and followup services. When problems have arisen in relation to equipment and hardware facilities, domestic enterprises have found it difficult to formulate immediate emergency solutions. ${ }^{10}$ As noted above, ECMO medical devices play a significant roles in the emergency treatment of severe COVID-19 patients. These devices involve a relatively complex and high-risk technology. They require a very high medical resource allocation and are characterized by high treatment costs. But compared with other cardiopulmonary bypass products, ECMO could provide longer time for treatment and recovery for cardiopulmonary failure patients, so ECMO has been applied to the rescue of critical patients for many times in this COVID-19 outbreak. The equipment is very expensive to use during non-epidemic periods and is not frequently selected as a treatment choice. Owing to multiple factors, including technology thresholds, clinical application restrictions, and market demand, China still lacks enterprises capable of producing ECMO equipment throughout the entire industrial chain.

\section{Weak Innovation Abilities of Enterprises and Insufficient Joint Innovations Among Different Subjects}

The characteristics of high-end medical device development-namely long investment cycles, large investment costs, and high risks - mean that the development of such products is dependent on large, long-term capital investments. European and American high-end medical equipment enterprises are mainly large multinational enterprises. Their primary sources of investment funds are the leading groups within the medical device industry and governments.

One of the characteristics of high-end medical devices is that the sales volumes tend to be small. Although the prices of such devices are relatively high, sales revenues may be low or sporadic. Class III medical devices generally need to go through 4-7 years of R\&D processes before a product goes on the market. During these testing periods, tens of millions of yuan in funds are required, and the capital and time input for developing an original product is generally double what may have been expected. Therefore, the R\&D expenditures can become a heavy burden for an independent R\&D unit producing Class III high-end medical devices.

In addition, original high-end medical equipment must be supported by basic research. The vast majority of enterprises are weak in terms of their independent R\&D capabilities, and do not attach great importance to the advanced nature of medical devices. Such enterprises are reluctant to invest in R\&D. They prefer to focus only on short-term business interests ${ }^{12}$ and are generally weak in anti-risk capabilities. In 2016, the expenditure by Chinese enterprises as a proportion of China's total basic research expenditure was only $3.2 \%$, which was far lower than that of enterprises in the United States (25.8\%), Japan (46.7\%), and South Korea (57.7\%). ${ }^{13}$ In addition, because these enterprises had not engaged in basic research for a long period of time, it was almost impossible for them to develop original high-end medical equipment. At present, a considerable number of companies are limited to playing the role of sellers or agents of advanced medical equipment for developed Western countries.

Some of China's current regulations exclude enterprises from undertaking basic research endeavors. Enterprises can only rely on universities and scientific research institutions to participate in basic research funded by the National Natural Science Foundation of China. These regulations are in sharp contrast to those faced by companies in Japan, the United States, and South Korea. In 2020, many large state-owned and private enterprises announced investments in the high-end medical equipment industry. However, they do not yet understand the longterm nature and R\&D laws of the industry.

The lack of joint innovations among different subjects and the lack of strong knowledge ties between key organizations tend to affect the institutional stability of the 
innovative medical equipment network. During the epidemic, some cutting-edge technologies were successfully combined with medical devices in application scenarios, such as disinfection robots and artificial intelligence (AI) medical imaging assisted diagnoses. However, at the present time, medical institutions and equipment manufacturers in China are mainly engaged in buying and selling relationships, with few carrying out medical trials and cooperative product development processes. In addition, factors such as China's special scientific research system, the existence of lags before China's local medical equipment meets international standards, and difficulties in overseas financing, are expected to have negative impacts on the development of joint international innovations.

The majority of high-end medical device enterprises in China are small- and medium-sized enterprises (SMEs). There is an urgent need to provide support for SMEs and reduce their financial risks through financial innovations. Medical institutions should have key roles in developing high-end medical equipment innovations. However, at the present time, medical devices and new technology are still in a state of separation, in that "those who understand technology do not understand medicine, and those who understand medicine do not know how to apply new technology". 14

Because doctors are evaluated by the number of patients they have treated and the number of papers they have published, they tend to work long hours, causing physical and mental exhaustion. Currently, Chinese medical institutions cannot participate effectively in the application of clinical technology through a joint innovation process. Moreover, manufacturing enterprises have encountered practical difficulties in participating in the joint innovations of the high-end medical equipment supply chain. ${ }^{14}$

\section{Low Technological Transformation Rates of Scientific Achievements in Research Institutes}

Although some research institutes have great advantages in conducting scientific research, the technique transformation rate is low. At present, the transformation rate of scientific and technological achievements in China is very low, at only $5 \%$. In recent years, the number of invention patents in China has increased significantly, such that China is ranked first in the world in this regard. However, the transformation rate is low, at approximately $10 \%$ on average, which is far lower than average of $30 \%$ to $40 \%$ in developed countries. In addition, the transformation rate of biomedical achievements in China has remained steady at approximately $5 \%,{ }^{15}$ and China's level of development in this regard is considered to be relatively backward when compared with other countries. Furthermore, there is no real equivalent of the U.S.' BayhDole Act in China. Bayh-Dole Act act was proposed by US senators Birch Bayh and Robert Dole. It was passed by Congress in 1980 and amended in 1984. Later, it was incorporated into Chapter 18, Part 35 of the Law Code (Patent Law), entitled "patents for federally funded inventions." Bayh-Dole Act has created a new realm of cooperation between technology and venture capital industry in the US The purpose of the bill is to encourage universities to carry out academic research and actively transfer patented technology, promote the development of small enterprises and promote industrial innovation by giving universities and non-profit research institutions the right to apply for and own the patent of inventions funded by the federal government. ${ }^{1}$ In China, any graduates with excellent medical qualifications tend to work in multinational companies and sell high-end medical equipment rather than engaging in new R\&D. As a result, the Chinese Academy of Sciences and other scientific research institutes have experienced a serious "brain drain" in recent years, with important talented individuals transferring to multinational enterprises. This has resulted in weakened R\&D abilities for the existing medical enterprises.

Although the "Law of the PRC for Promoting the Transformation of Scientific and Technological Achievements", based on the benchmark of the BayhDole Act, was formally implemented on October 1, 1996, it has not achieved the desired effects. Over the years, scientific research institutes or universities have been limited either by the fear of losing state-owned assets or by the existing assessment system, and have failed to adequately invest in the transformation of science and technology. In the past, whereas China's scientific research achievements were focused on high-end research and applications, China's industries were focused on the middle- and low-end product range. This has resulted in an enormous gap between scientific research and industry. Under China's current science and technology evaluation system, researchers are mainly evaluated in terms of papers published and projects won. Although the state has issued policies to encourage researchers to start their own businesses, there are many links, long cycles, and uncontrollable risks in technology transformation from 
the source mechanisms to practical, mature products. Often, scientific research institutions cannot provide adequate platforms and support. Therefore, there have been few successful cases of scientific research driving entrepreneurship.

Conversely, many positive cases of the successful transformation of scientific and technological achievements by scientific research institutes have been reported. In February 2017, the Laboratory of Cryobiology of the Technical Institute of Physics and Chemistry at the Chinese Academy of Sciences developed innovative medical instruments, including the cryobiosurgical system and the disposable sterile cryobiosurgical ablation needle, which can be used for clinical cryotherapy of certain solid tumors. Within 10 years of the development of the prototype, the institute had successively transferred the technology to a medical device company, and the device was approved by the China Food and Drug Administration.

\section{Development Opportunities Presented by High-End Medical Equipment Innovations in China (O)}

The medical device industry is a strategic science and technology industry related to national public health safety, which is at the high end of the value chain and the core of the industrial chain. Currently, new generations of biological, informational, and manufacturing technologies are rapidly converging in the field of medical equipment. The international competitiveness of medical equipment has become a prerequisite for the restructuring of the global value chain. The integration of the various emerging technologies for medical equipment provides opportunities for countries that developed later to catch up.

\section{National Policy Support for High-End Medical Equipment}

In recent years, the central government of China has been actively supporting the domestic medical equipment industry. In the 12th Five-Year Plan for 2010-2015, large medical equipment devices were listed in the critical area of "cultivating and developing strategic emerging industries". In addition, the "Made in China 2025" (《中国制造 $2025 \gg$ ) policy initiated by the State Council in May 2015 mentioned that, in terms of biomedicine and high-performance medical devices, improvements should be made in the innovation abilities and the level of industrialization of medical devices. Focus was placed on the development of imaging equipment, medical robots, and other high-performance medical equipment. ${ }^{16}$ As pointed out in the 2016 Outlines on National Strategy for Innovation Driven Development (国家创新驱动发展战略 纲要), long-standing or so-called "around the neck" issues (卡脖子问题) related to long-term development and national security should be strengthened by the implementation of forward-looking plans for basic research. Furthermore, efforts should be increased in major basic research and strategic high-tech research in bioscience and other fields to realize security, autonomy, and controllability of key technologies. In the 13th Five-Year Plan (十三 五规划) for 2016-2020, not only medical devices but also "high-performance medical devices" were included, listed as one of eight fields of "high-end equipment innovation and development projects". Furthermore, in recent years, the central government and local governments have issued a series of policies to promote the substitution of domestic products for imported ones. Such policies have included optimizing registration and approval processes, scientific research subsidies, selection of domestic products as eligible for medical insurance, and encouraging hospitals' usage of domestic products as a priority. In 2019 alone, 19 innovative medical devices were approved, including positron emission tomography and magnetic resonance imaging.

\section{China's Science and Technology Plans in Major Fields of Medical Equipment}

During the period of the 13th Five-Year Plan, the Ministry of Science and Technology established a digital diagnosis and treatment equipment $R \& D$ project, which aimed at seizing the opportunities presented by a new round of the scientific and technological revolution in the field of health. The goal was to systematically strengthen China's abilities to address problems related to the core components and key technologies of 10 major strategic products. These included multimodal molecular imaging and large radiotherapy equipment used in early diagnosis detections, accurate diagnosis processes, minimally invasive treatments, and accurate treatments according to the principle of whole-chain deployment. Then, through integrated implementation and focusing on breaking through a number of leading-edge technologies, improvements in testing technology could be promoted, and the integration 
of innovation chains and industrial chains could be successfully accelerated in China's medical device industry.

After many years of development and accumulation, China's domestic medical devices have been greatly improved from the aspects of equipment performance and stability, scientific and technological content, operation experience, and serviceability. The gaps with imported products have gradually narrowed and the pace of the localization of high-end medical devices has accelerated. The Proposal of the CPC Central Committee on Formulating the Fourteenth Five-Year Plan for National Economic and Social Development and the Long-range objects for the year 2035 (《中共中央关于制定国民经 济和社会发展第十四个五年规划和二 $\bigcirc$ 三五年远景目 标的建议》),

which defines the strategic thinking cerning innovation-driven, high-quality development during the next 5 years, reached its resolution on March 11, 2021 at the fourth session of the 13th National People's Congress. It is certain that China will plan improvements in relation to additional major medical device categories to further progress its independent control of high-end medical equipment. It is expected that the advances in the medical device industry will usher in a period of "golden opportunity". 17

\section{Threats/Risks to High-End Medical Equipment Innovations in China ( $T$ )}

This section will explore the threats and sources of risk to innovation in high-end medical equipment in China based on the key stages in the whole life cycle of such innovation.

\section{Weak R\&D Abilities of Enterprises Facing Diversified Markets}

Although it has long been a goal to substitute domestic products for imported products, the situation has recently changed. Although secondary innovations have enabled the domestic medical devices industry to achieve partial autonomy, this has only addressed the short-term survival needs of the enterprises. As a result, medical device firms have not been able to expand beyond low-end manufacturing until recently. Therefore, policy support for import substitution can potentially ensure that some domestic medical device enterprises possess a share of the market. However, to ensure their longer-term survival and competitiveness, these firms will need to face changing market demands and ensure they have the capacity for continuous innovation and transformation that is urgently required by domestic medical device enterprises.

The trade friction between China and the United States began after China's initial success in developing its highend domestic medical equipment industry. The United States seized on the high-tech weakness of China, first by punishing ZTE, and then repeatedly curbing Huawei. Moreover, the United States announced plans to impose additional tariffs on China in the fields of highperformance medical devices, biomedicine, agricultural machinery and equipment, and industrial robots. Therefore, in this context, enterprises that had been weak in terms of their R\&D capabilities faced competitive, diversified markets. To survive in this context, they were gofeed to break through technological barriers, which then enhanced the autonomy and sovereignty of the domestic medical equipment industry. In this new context, the firms in the high-end medical equipment industry had to review their risk management for their entire production processes, including undertaking risk analyses during the identification stage and risk evaluations after identification, implementing control measures for the identified risks, and designing operation strategies for remaining risks that could not be controlled.

\section{Lag Times in Registration and Price} Approval Processes Lead to Long Clinical Application Cycles for Some New Medical Equipment Products with the Main Responsibility for Equipment Safety Held by the Regulatory Department

The approval timeframes for drugs and medical devices are lengthy and involve many steps. This has been a major problem in the past for the medical industry. Even now, it commonly takes 2 to 3 years to complete the registration of a new high-end medical device, from the product application and registration to the final registration certificate. In some cases, the process may take 4 or 5 years, or even longer.

The majority of high-end medical devices are classified as Class III medical devices, and the registration of such devices is approved by relevant national departments. Each year, a large number of products are submitted for approval in China, and the disciplines involved are complex. However, the number of reviewers is very limited, and the approval system lacks inspection equipment, 
personnel, and standards for innovative products. Often, therefore, the registration and inspection of medical devices is delayed, and may take years to complete. Some enterprises are reluctant to develop new products because of the requirement to commit to 1-2 years of clinical trials and to invest several million yuan in funding. In February 2014, the State Food and Drug Administration of China issued the "Special Approval Procedure for China's Innovative Medical Devices (Trial)", which proposed setting up a "green channel" for the approval of innovative medical devices to give priority to such devices. The State Council and the National Development and Reform Commission required that the collection of drug inspection fees and medical device product inspection fees cease from April 1, 2017. ${ }^{18}$ However, free inspections have exacerbated the congestion phenomenon.

Unfortunately, the product registration processes were not made any easier, even with special approval. ${ }^{8}$ In addition to the lack of sufficient reviewers, the unclear approval standards and some redundant links were important reasons for the continued long delays in registration and approval. At the present time, there is no clear standard for the review and approval of medical devices involving new technologies.

In accordance with the relevant regulations, clinical trials of medical devices should be reviewed by the ethics committee of the testing institution. The ethics committee of a hospital usually holds a meeting every 2 to 6 months, and there are a limited number of experimental projects reviewed at each meeting. To improve the timeliness of the reviews, some enterprises have been required to absorb added costs and build public relations through interpersonal networks.

Even if an enterprise obtains a product registration certificate, because the medical services of China's nonprofit medical institutions are priced following government standards, the public hospitals must determine the charges for new medical devices by applying to the local price, health, and social security departments. Currently, owing to the differences in prices and medical insurance policies, the implementation of price audits varies among different regions.

Some companies have successfully acquired the relevant technology for high-end emergency medical equipment through overseas mergers and the equipment development have then localized. However, it will still take several years to obtain domestic registration certificates for the devices to sell them within China. The aforementioned companies are required to export the equipment to the United States and then import it back to China. As a result of the tedious and long approval process, some enterprises have given up on selling in the domestic market and focused on expansion in overseas markets. Even if the products of some companies have been registered in the European Union and the United States, clinical trials are required in China if the companies wish to sell their products in China. In contrast, the majority of foreign brands do not encounter such requirements. ${ }^{19}$ The long approval times make it difficult for some companies to convert the technology in which they have invested large amounts of capital, which sometimes results in bankruptcy.

Due to China's late start in the medical device industry, along with insufficient technology precipitation and accumulation, the majority of the industry's enterprises are small in scale and cannot bear high costs. In response to the sudden outbreak of COVID-19, the National Medical Products Administration launched an emergency review, introduced more timely approval procedures for medical devices, and approved a large number of medical devices required for epidemic prevention and control. However, the problems of the long approval cycles for innovative medical equipment have not yet been fundamentally solved.

New medical devices are required to pass the price approval processes of government departments before they can be entered into the list of approved hospital charges and be purchased by hospitals. However, the promotion of innovative medical devices, particularly products originating overseas, is a rather long process. For example, enterprises need to deal with the price approval processes of each province separately. It often takes more than 3 years for a series of processes to be completed, such as the necessary understanding of the products by the doctors, recognition of the products, and approval of the capital budget and bidding procurement by the relevant hospital. These multiple steps mean that enterprises receive no income from newly listed products in the first few years, which is often untenable for SMEs. Even after entering the list of approved charges, there is a lack of uniform pricing standards, with domestic devices generally priced much lower than imported products.

Because the localization of medical equipment in China remains limited, the domestic market (for example, hospitals and medical personnel) is highly dependent on 
multinational companies and products. Consequently, as multinational companies have strong marketing abilities and public hospitals continue to ignore cost effectiveness and use imported equipment, some high-quality domestic products remain difficult to procure locally. Although the state has issued a number of policies to encourage the purchase of domestic high-end medical devices, there continues to be a "glass door" phenomenon in the actual bidding processes.

\section{Lack of regulation after medical equipment comes on the market}

The increasing number of adverse events associated with medical device in China in recent years reflects the lack of risk management, which is an important source of risk in high-end medical equipment innovation in China.

In China, the risk management processes for drugs are relatively mature. However, the majority of medical device companies only submit risk management documents at the time of registration. Essentially, such companies do not carry out risk management processes after production, which results in increased likelihood of adverse events being associated with the medical device. ${ }^{20}$

As an embedded management method, risk management needs to play a role in the entire process of a medical enterprise's product, including designs, changes, deviations, complaints, and inspection, both internal and external, of defects. In addition, because of the lack of security measures for the Internet of Things devices, medical devices connected to the Internet can easily become the targets of hackers, which presents major security risks. On the one hand, medical equipment is often related to the personal safety of patients. On the other hand, hackers can potentially steal private medical information as the medical devices are connected to hospital network systems. Therefore, prior to approving products entering the global market, the FDA (Food and Drug Administration) considers the network security levels as an important factor and provides relevant guidance. Given this, the security of medical data generated by medical equipment in China should also be worthy of attention.

\section{Government centralized procurement is restricted by distributor monopolies in the sales channels and shortages in the domestic medical equipment market}

Previously, sales of medical equipment in China were dominated by distributors. The distributors monopolies provided opportunities for price profiteering, which resulted in excessively high pricing of medical devices. Whereas in the United Kingdom and Germany, pricing methods are based on government regulation or medical insurance systems, Chinese medical equipment manufacturers retain independent pricing power. They are required to publicize the product information on the procurement platform of different provinces, and then medical institutions purchase devices listed on the platform. However, the actual operation of the bidding and procurement on the network is quite complex. For example, purchasers must often deal with bidding and procurement offices, as well as industry and commerce departments, food and drug administrations, hospital leaders, doctors, and other decisionmakers. In addition, similar processes need to be repeated in each province. Moreover, the middle multi-layer dealer networks, as well as the small and scattered dealer networks from manufacturing enterprises to hospitals, may resist supervision.

To address these issues and break dealer monopolies, a centralized governmental procurement for medical devices may be a solution. For example, in 2020, the government's centralized procurement of domestic heart stents reduced their price by $90 \%$. However, the localization rate of heart stents was very high and the market was mature. At present, these preconditions for centralized procurement do not exist in other areas.

\section{Strategic Analysis of the Innovation and Development of China's High- End Medical Equipment Based on an ANP-SWOT Model}

\section{Analysis Method}

The main decision-making steps in our ANP-SWOT model were as follows.

1. A SWOT model was used to identify the factors influencing the development of China's high-end medical equipment industry; formulate the strategic alternatives for the development of medical equipment; and establish the ANP structure model, as shown in Figure 1. The development of China's high-end medical equipment was regarded as the overall goal of the ANP model. The internal and external factors contained in the four factor sets of the SWOT analysis were taken as the criterion layer of the model, and the strategic alternatives formulated by the SWOT matrix were used as its scheme layer. 




Figure I ANP-SWOT structure model.

(2) Through an expert evaluation process, a pairwise comparison matrix was constructed. Comparisons of the paired elements, including their importance under the control criterion, were conducted. The relative importance values were determined using a Saaty 1-9 scale, as detailed in Supplementary Table S1. In addition, the experts' judgment preferences were required to pass a consistency test. Then, the maximum eigenvalue $\lambda \max$ of the pairwise comparison matrix and its corresponding eigenvector $\omega$ was calculated as follows:

$$
\begin{gathered}
\mathrm{CI}=\lambda_{\max }-\mathrm{n} / \mathrm{n}-1 \\
\mathrm{CR}=\frac{\mathrm{CI}}{\mathrm{RI}}
\end{gathered}
$$

where CI represents the index of the degree of inconsistency, RI is the average random consistency index, set according to the order $\mathrm{n}$ of the judgment matrix (Supplementary Table S2), and CR indicates the consistency ratio of the pairwise judgment matrix. When $\mathrm{CR} \leq$ 0.1 , it is considered that the judgment matrix is consistent, and the calculated $\omega$ is acceptable However, when $\mathrm{CR} \geq$ 0.1 , the judgment matrix should be appropriately modified.

(3) The eigenvectors corresponding to the maximum eigenvalues of the judgment matrices are calculated to obtain the weights of the judgment objects.
In accordance with the internal and external factors influencing the development of China's high-end medical equipment industry, a SWOT analysis matrix was constructed, as detailed in Table 1.

On the basis of the current situation, under a specific environment of "demand plus innovation" forefronting the development of the industry, the next decade will be a golden age of innovation for domestic medical devices. To assist China's high-end medical equipment industry to innovate more efficiently and avoid any innovation traps, we put forward the policy suggestions below.

\section{Policy Suggestions Under the Strength and Opportunity (SO) Mode}

Tackling key scientific and technological problems under a new national system should be combined with international cooperation and local initiatives. Focus should be placed on the common key technologies of medical equipment and collaborative and integrated innovations in medicine, research, and enterprise, and technological applications should be actively promoted. High-end medical device innovations cannot be "built behind closed doors" and China needs to keep pace with the global technology frontier. Therefore, we suggest that international capital operations should be encouraged under the 
Table I SWOT Analysis Matrix for the Development of China's High-End Medical Equipment Industry

\begin{tabular}{|c|c|c|}
\hline & Strength & Weakness \\
\hline & $\begin{array}{l}\text { Tackling of key problems related to science } \\
\text { and technology under the national system; } \\
\text { Industrial and medical integrated innovations, } \\
\text { and cooperation between large hospitals and } \\
\text { enterprises in regard to clinical verifications } \\
\text { and scientific research; } \\
\text { More diversified industrial investors; } \\
\text { Emergence of some influential industry giants }\end{array}$ & $\begin{array}{l}\text { Domestic market is monopolized by } \\
\text { multinational companies; } \\
\text { Shortages in core technology and parts; } \\
\text { Weak innovation abilities of the enterprises; } \\
\text { Joint innovations among different subjects is } \\
\text { insufficient; } \\
\text { Transformation rates of scientific and } \\
\text { technological achievements in scientific } \\
\text { research institutes are low }\end{array}$ \\
\hline Opportunities & SO & WO \\
\hline $\begin{array}{l}\text { National policy support; } \\
\text { Layout of I4th Five- Year Plan includes the } \\
\text { major fields of medical equipment }\end{array}$ & $\begin{array}{l}\text { Tackling of key scientific and technological } \\
\text { problems under the new national system } \\
\text { should be combined with international } \\
\text { cooperation and local initiatives; } \\
\text { Priority should be given to the purchase of } \\
\text { high-quality domestic products, with the } \\
\text { government hopefully strengthening } \\
\text { centralized purchase processes; } \\
\text { New medical technology innovations brought } \\
\text { into the medical insurance management } \\
\text { process as a priority }\end{array}$ & $\begin{array}{l}\text { Speed up the construction and improvement } \\
\text { of the enterprise-dominated, market-oriented, } \\
\text { industry and university research combined } \\
\text { with technological innovation systems; } \\
\text { Increase financial support for research and } \\
\text { development and industrialization; } \\
\text { Strong governmental support through taxes, } \\
\text { medical insurance, talent, and land usage }\end{array}$ \\
\hline Threats & ST & WT \\
\hline $\begin{array}{l}\text { Long registration cycles and review processes } \\
\text { for newly developed medical equipment; } \\
\text { Under the negative effects of trade friction, } \\
\text { enterprises have weak research and } \\
\text { development abilities in the face of diversified } \\
\text { markets; } \\
\text { Lack of supervision of medical equipment } \\
\text { after entering the market; } \\
\text { Centralized government procurements are } \\
\text { restricted by the dealer monopolies and the } \\
\text { lack of marketization for domestic medical } \\
\text { equipment }\end{array}$ & $\begin{array}{l}\text { Strengthen investments in research and } \\
\text { development and encourage investment and } \\
\text { acquisition processes in order to strengthen } \\
\text { weak links; } \\
\text { Provide professional services for the } \\
\text { technological innovations of small- and } \\
\text { medium-sized enterprises with the support of } \\
\text { a technical service platform; } \\
\text { Develop supporting industries; } \\
\text { Align with international standards to improve } \\
\text { standards and regulations }\end{array}$ & $\begin{array}{l}\text { Deepen the reform processes of the product } \\
\text { reviews and approval systems and open up } \\
\text { some socialized reviews and approval links; } \\
\text { Start risk management activities in the entire } \\
\text { life cycles of high-end medical devices and set } \\
\text { up risk management teams; } \\
\text { Highlight the main responsibilities of } \\
\text { enterprises and strengthen the detections of } \\
\text { adverse events after the high-end medical } \\
\text { equipment enter the market }\end{array}$ \\
\hline
\end{tabular}

joint enterprise constructions of "One Belt and One Road" and "Going Global". In addition, capital mergers and acquisitions should be undertaken to aid adoption and understanding of new technologies to assist in ultimately achieving independent $R \& D$ and production capacities in China. At the same time, local initiatives should receive appropriate attention. With the support of representatives from the Ministry of Science and Technology, Ministry of Health, China National Medical Products Administration, Ministry of Civil Affairs, Health Department of General Logistics Department of PLA, Ministry of Education, China Association for Medical Devices Industry, China
Disabled Persons' Federation, Chinese Academy of Sciences and other relevant member units of the alliance, after the establishment of China Medical Device Industry China Industry Technology Innovation Strategic Alliance in Beijing on June 17, 2009. ${ }^{21}$ The operation strategy and practical experience of such Alliance can be learned from Chengdu, Shanghai and Zhejiang's experience in establishing a medical equipment industry innovation alliance, in which regional enterprises, institutions, and investment and financing institutions in the field of medical devices were successfully connected. ${ }^{22-24}$ As a result, the integration of industry, university, and research applications was 
promoted, with coordinated development of the upstream and downstream industries within the region. In this way, the clinical trials and achievements in transforming medical equipment products could be accelerated, with the goal of building a 100 billion yuan high-end medical equipment industry cluster.

Priority should be given to the purchase of high-quality domestic products, with the expectation that the government will strengthen centralized purchases. The current "Selection Catalog of Excellent Domestic Medical Equipment Products" is only utilized as a reference for local procurements and has not been promoted nationwide. It is suggested that incentives be increased and hospitals that give priority to purchasing domestic high-quality products be given preference in regard to medical insurance and other aspects. Such measures will assist SMEs to survive and grow.

Bringing new medical technology innovations into the medical insurance management processes is an important priority. China has not yet implemented universal medical insurance, and it will take many years for new medical technology to be included in medical insurance processes. Until recently, new medical technology was a self-paying medical item, which greatly affected the applications of new medical technology and the viability of such products for enterprises. In the future, it is expected that innovative medical technology will be prioritized in medical insurance management processes after 2 years of clinical applications, to enhance the market competitiveness of innovative medical device firms.

\section{Policy Suggestions Under the Mode of WO (Weaknesses and Opportunities)}

China should speed up the construction and improvement of enterprise-dominated technological innovation systems. The construction and improvement of enterprisedominated, market-oriented, joint industry-university technological research innovation systems should be enhanced to speed up these processes. Given that, at present, some upstream raw materials and key components used in the production of high-end medical equipment are dependent on imported materials, it is vital to continuously strengthen investments in $\mathrm{R} \& \mathrm{D}$, as well as upstream joint industry-university research. If such measures are undertaken, it is likely to promote breakthroughs and the realization of a transformation in China's industry from imitation to innovation. However, the learning and mastering of core technology through investment and acquisition should be encouraged, with the goal of realizing cooperative and iterative innovations on that basis. ${ }^{10}$

Medical and industrial collaborative innovations are an important means of compensating for the shortcomings of China's high-end medical equipment industry. Since the outbreak of COVID-19, the Ministry of Industry and Information Technology of China has repeatedly deployed high-end medical equipment to address these shortcomings, emphasizing the close integration of medical equipment R\&D and clinical application processes, and promoting engineering responses to key problems related to the medical treatment equipment. ${ }^{25}$

However, it is necessary to standardize and accumulate the industrial and application data concerning design, production, clinical usage, and maintenance of medical equipment, to give full play to the industrialization and applications of big data service platforms for high-end medical equipment and to realize data interconnection. Therefore, it is urgent that China catches up with the new trends in high-end medical device technology, accelerates the applications of AI, and applies for characteristic invention patents. China has made advances in the treatments of gastric cancer, liver cancer, and other specific diseases involving genetic susceptibility. Therefore, it is considered that through the deep learning of AI, differentiation advantages can be accumulated.

A key policy tool is to increase financial support for $\mathrm{R} \& \mathrm{D}$ and industrialization processes. Currently, SMEs are the most innovative enterprise groups in China. Therefore, we suggest that financial support for $R \& D$ and industrialization should be increased. In addition, industrial development funds, government equity investment funds, and other financial innovations should be established, and government industrial funds be utilized for investment guidance. Further, more public funds should be invested in the field of high-end medical devices to alleviate the financing difficulties of SMEs, and to encourage such enterprises to increase their R\&D investments. In addition, we suggest that the sustainability of subsidies for $R \& D$ into innovative domestic products should be maintained by further increasing the number of special fund subsidy programs and enhancing the scientific and technological competitiveness of domestic enterprises.

The policy of strengthening government support through taxes, medical insurance, promoting talent, and appropriate land usage should not be overlooked. To realize the independent and autonomous domestic production of medical devices and achieve quality levels that match 
those of international products, it is important that the government provide strong support through taxes, medical insurance, promotion of talent, and the provision of capital and land. This will provide the basic preconditions for the development of China's high-end medical device industry, in addition to improving the innovation abilities of domestic enterprises.

As the development of China's medical device industry began late compared with that of other countries and it lacks large producers, major support will be required. We suggest that the industry associations should take the lead in solving the problems related to attracting and retaining talent, listing and financing, equity incentives, market applications, domestic base construction, and so on. At the same time, support should be given to leading enterprises in driving international cooperation in high-end medical services and related supporting industries by making use of domestic and foreign resources. ${ }^{26}$

We recommend that support for high-level talent should be enhanced to lay a solid foundation for innovation and development. As the development of original high-end medical devices requires a large number of highly skilled workers, and the time cycles from project approval to income are often very long, it has limited appeal for high-level talents. Moreover, the various conditions for SMEs impose restrictions. However, with the rapid changes in the international situation, returning to the Chinese mainland is increasingly more appealing to highly talented workers. We suggest that government departments should introduce various policies to address the concerns of high-level talent, so that they can assist SMEs to achieve important breakthroughs in technology accumulation.

Another important issue is the reduction of the tax burdens of technology SMEs. The sales value-added taxes of products with a high technology content and high added value could be given preferential treatment to reduce the tax burden of science and technology SMEs. Furthermore, appropriate preferential treatment should be given to such enterprises in relation to the rental of production and office sites, as well as land usage.

New policies and personnel training for innovations involving an integration between the medical and industrial fields should be implemented. This combination of the fields of medicine and industry will become the new model of interdisciplinary medical research and an important method for the development of modern medicine. ${ }^{27}$ However, to implement joint medical-industrial innovations, new biomedical engineering talents will be needed. Such talents should combine science, engineering, and medical knowledge, and the knowledge of other relevant disciplines, to benefit from the " $1+1$ is greater than 2 principle". 28

\section{Policy Suggestions Under the ST (Strengths and Threats) Thinking Mode}

It is important to increase investments in R\&D and encourage investments and acquisitions to strengthen China's weak links. The provision of professional services for the technological innovations of SMEs with technical service platforms as support, should be considered.

The enterprises with successful experience should be encouraged to develop as platforms or incubator enterprises to provide services to assist others in reducing product $R \& D$ cycles and speeding up the marketing of innovative products. These specialized services will encourage and support the technological innovations of SMEs.

By focusing on key industrial chains and using leading enterprises to drive the upstream and downstream support of SMEs, particularly "professional, refined, special, and innovative" SMEs, major progress can be achieved. At the same time, high-grade, precision, and advanced industrial products can be developed and the so-called technological "no man's land" can be explored. Therefore, it is recommended that vigorous support should be given to the basic development of supporting industries, which are related to the industrial and innovation chains of high-end medical devices, and to realizing high-scale production and highlevel professional divisions of labor. These measures will not only be conducive to improving China's high-end medical device industry, but also the global industry.

International standards are of major significance for ensuring the safety and effectiveness of medical equipment and improving the efficiency of supervision. China is a member of the International Medical Device Regulators Forum. In the future, China will improve its consistency with international standards and promote mutual recognition using these international standards. At the same time, China should strive to reduce the frequency with which relevant laws and standards are revised and establish an effective revision mechanism. ${ }^{26}$

\section{Policy Suggestions Under the WT (Weaknesses and Threats) Thinking Mode}

To promote medical equipment innovations, it is important to simplify the review and approval procedures and open 
up socialized review and approval processes. In 2018, the Chinese government abolished the compulsory registration and inspection of high-end medical devices. This helped spur enterprises to take responsibility for and improve their self-inspection abilities. However, there remains room for reform to address such problems as the lengthy application and registration times for high-end medical equipment, the long queues for approval, and the difficulties in being added to lists approving the fees that can be charged by public hospitals and lists approving medical insurance coverage.

We suggest that some public review and approval links should be opened up as soon as possible. There is much to be learned from the management experience of the United States and the European Union in regard to optimization and defining the catalog of Class III medical devices. In addition, there is valuable information available regarding piloting the separation of testing, evaluations, and certification of Class III medical devices, as well as handing over product testing to professional market-oriented testing institutions. This would allow enterprises to perform self-testing to meet the formulations of extremely strict regulatory measures and reduce the excessive backlog of medical equipment awaiting registration. Severe punishment would be imposed in the case of fraud by testing institutions and enterprises. More third-party testing institutions can be authorized to test Class III medical devices, and the technical approval processes can be transferred to some provinces and cities on a pilot basis before being checked and certified by relevant national departments.

Medical insurance departments should ensure innovative medical device products with registration certificates are brought into the catalog in a timely manner, and stipulate that once these devices enter one catalog, they can automatically enter the catalogs of other provinces and cities. Then, more third-party professional medical device testing institutions that have been qualified in accordance with legal procedures can be authorized to test Class III medical devices and ensure appropriate service and supervision.

Reform of the review and approval systems should be undertaken to accelerate the market applications of new products. When updating established products, or introducing foreign technologies that have been clinically tested, the National Medical Products Administration can learn from the review system of the founding countries of the Global Harmonization Task Force to further improve preconsultation systems and reduce unnecessary approval delays. In addition, for products that are already approved by the Global Harmonization Task Force, the approval procedures in China should be simplified. ${ }^{26}$

As the use of any medical device involves a certain degree of risk, it is important to balance innovation with safety during high-end medical equipment production. Risk management activities should be conducted during the entire life cycle of a high-end medical device, and risk management teams should be established. In other words, risk identification processes should be carried out and corresponding risk management plans should be made during the planning, design, and development stages of the equipment. When formulating risk acceptability criteria, consideration should be given to the capacity and cost, and a risk-return balance accepted by all parties should be established. Risk assessments should be conducted according to the acceptable risk criteria of all parties to determine whether control measures are needed and what measures should be taken to reduce and control risks. At the same time, attention should be paid to improving the emergency reserve mechanisms of highend medical devices, as well as clarifying the main responsibilities of the manufacturers, business units, and users of the medical devices. In addition, regulations should make it mandatory to report any adverse events associated with medical devices.

We recommend that the registration approval rules and standards, as well as the authority and responsibilities of the approval personnel, should be further clarified and made transparent. Approval personnel should be exempted from responsibility as long as they have followed the corresponding procedures to avoid any adverse effects of a "whoever approves is responsible" culture on approval personnel and approvals. In addition, policies should be implemented to ensure that the enterprises that produced the high-end medical equipment are responsible for any adverse events after the equipment enters the market, rather than the equipment inspection parties being held responsible. At the same time, hospital ethics committees should focus on protecting the rights and interests of clinical trials, and provincial management departments should organize experts to evaluate the effectiveness of the clinical trials of Class III medical devices.

The implementation of the "Measures for the Management of the Monitoring and Reevaluation of Medical Device Adverse Events" should be actively promoted, and the construction of systematic and complete adverse event monitoring systems, with clear responsibilities 
and divisions of labor, should be accelerated. The production enterprises should be supervised and urged to register as system users. In addition, the primary responsibilities of the enterprises, along with their reporting responsibilities, should be further clarified. There is a need to strengthen the current systems for analyzing and controlling daily detected risk signals and ensure that a closed-loop management of risk signals is effectively carried out. Improvements to the information systems and early warning signal rules are necessary to further enhance risk discovery, risk analysis, early risk warnings, and risk disposal processes. As a result of the strengthening of the monitoring and disposal processes, control measures for adverse events found during the monitoring processes - such as early warnings, inspections, repairs, re-labeling, modifications of instructions, software upgrades, replacements, recovery, and destructioncan be carried out according to the degree of harm and causes of the adverse events, with any potential risks quickly resolved. $^{2}$

\section{Analysis of the Development Strategy of China's High-End Medical Equipment Industry Based on an ANP-SWOT Model}

Step 1: Build the network hierarchy

Taking the development of China's high-end medical equipment as the overall goal, and using the 14 influencing factors as the criterion layers, a network hierarchy diagram of China's high-end medical equipment development was constructed, using a strategic plan formulated by a SWOT matrix as the scheme layer, as shown in Figure 2. Experts were invited to determine the relationships between the factors, as shown in Figure 3.

Step 2: Evaluation of the importance of influencing factor sets

Using an expert consultation method, a number of experts in the field were selected and invited via a questionnaire survey to score the levels of importance of the influencing factors for the index system. Then, the scoring results were discussed and summarized internally to obtain the pairwise discriminant matrix and weight values, as detailed in Table 2 .

MATLAB software was used to calculate the maximum eigenvalue $\lambda_{\max }=4.0788$ of the judgment matrix $S$. In addition, to test the consistency of the judgment matrix, the consistency index was calculated as follows:

$$
C I=\frac{\lambda_{\max }-n}{n-1}=\frac{4.0788-4}{4-1}=0.0263
$$

The average random consistency index was $R I=0.9$, and the random consistency ratio was determined using the following equation:

$$
C R=\frac{C I}{R I}=\frac{0.0263}{0.89}=0.0295<0.10
$$

In summary, it was considered that the results of the analytical hierarchy process had satisfactory consistency. That is to say, the distribution of the weight coefficients was very reasonable.

Step 3: Study and judge the levels of importance of the influencing factors

First, we assumed that there were no dependence or feedback relationships between the influencing factors. The pairwise comparison matrix of the influencing factors is shown in supplementary Tables $\mathrm{S} 3$ to $\underline{\mathrm{S} 7}$. The weights of the influencing factors $\omega_{1}$ obtained under the assumed conditions are detailed in Table 3.

Now, assuming that there are dependence and feedback relationships, the pairwise comparison matrix of the relevant factors is shown in supplementary Tables S7 to S11. The matrix is in accordance with the relationships between the internal and external influencing factors given in Figure 3. The obtained relative importance weights were used to generate the unweighted super-matrix $\omega_{2}$, as shown in Table 4.

Then, the weights $\omega_{\text {factor }}$ of the 14 internal and external factors under the overall goal were obtained as follow:

$\omega_{\text {factor }}=\omega_{2} \cdot \omega_{1}=(0.1425 ; 0.0237 ; 0.069 ; 0.0382 ; 0.0795 ;$ $0.1169 ; 0.1085$;

$0.0813 ; 0.1773 ; 0.1418 ; 0.0197 ; 0.0676 ; 0.011 ; 0.009)^{\mathrm{T}}$

As determined from the weight values, the most influential factor for China's medical equipment industry development was national policy support for high-end medical equipment (0.1773). In addition, this factor was an important reason explaining why China attaches major importance to $R \& D$ in medical equipment and has recently achieved an increasing market share in this industry.

In exploring the adverse factors for the development of medical equipment in China, the following stood out: the shortage of core technology and parts of high-end medical equipment (0.1169); the lack of innovative abilities of the enterprises themselves $(0.1085)$; the late start of the high-end medical equipment industry in China and the monopolization of the domestic market by 
Development of high-

end medical equipment in China

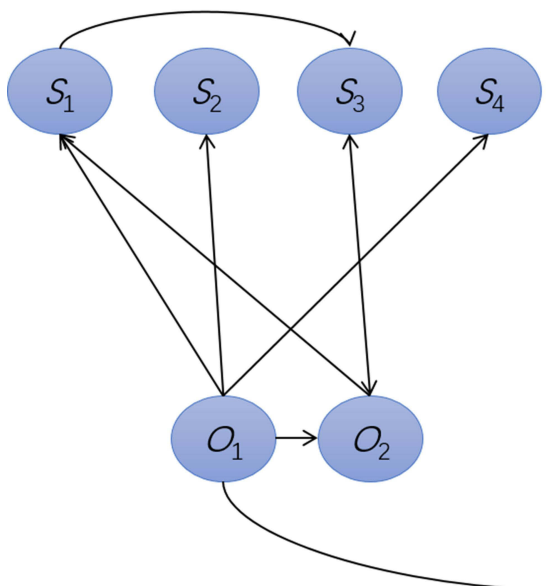

Tackling of key problems of core technology through the national system $\left(\mathrm{S}_{1}\right)$

Emergence of international high-end medical

equipment industry giants $\left(S_{2}\right)$

Significant trend of integration of industry and

medicine $\left(\mathrm{S}_{3}\right)$

Diversification of investors $\left(S_{4}\right)$

Late start of domestic high-end medical equipment

\section{$\left(W_{1}\right)$}

Shortage of core technology and parts of high-end

medical equipment $\left(W_{2}\right)$

Weak innovation ability of enterprise itself $\left(W_{3}\right)$

Weakness (W)

Low transformation rate of scientific and technological achievements in scientific research institutes $\left(W_{4}\right)$

Opportunity $(\mathrm{O})$

Threat $(\mathrm{T})$
National policy support $\left(\mathrm{O}_{1}\right)$

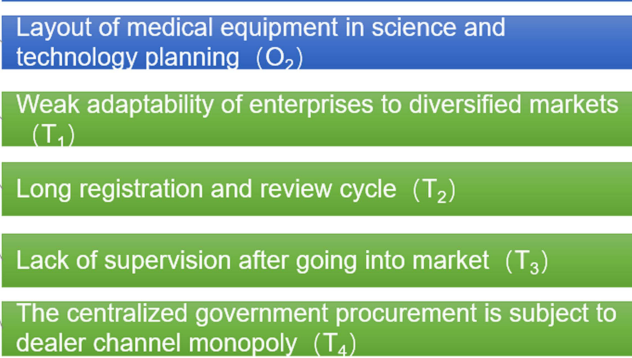

SO strategy

ST strategy

Figure 2 Hierarchical structure of China's high-end medical equipment development network.

Figure 3 Relationships between the internal and external factors.

multinational companies (0.0795); and the long registration and review cycle for innovative high-end medical equipment (0.0676). Among these factors, the shortage of core technology and components for high-end medical equipment and the enterprises' lack of innovative abilities were considered to be the key factors restricting the innovation and development of China's high-end medical equipment industry. Therefore, it is necessary to diversify capital investment and establish a national policy guarantee system, as well as to strengthen the investments in China's high-end medical equipment. Furthermore, enterprises should be required to take reasonable measures to avoid risks according to the characteristics of $\mathrm{R} \& \mathrm{D}$, transformation, and approval of medical devices based on the development of the existing medical device industry. 
Table 2 Pairwise Comparison Matrix of the Various Influencing Factor Sets Under the Overall Goal

\begin{tabular}{|l|r|r|r|r|r|}
\hline & Strength (S) & Weakness (W) & Opportunity (O) & Threat (T) & Weight \\
\hline Strength (S) & $\mathrm{I}$ & $\mathrm{I} / 3$ & 2 & 3 & 0.2409 \\
Weakness (W) & 3 & $\mathrm{I}$ & 3 & 5 & 0.5272 \\
Opportunity (O) & $\mathrm{I} / 2$ & $\mathrm{I}$ & $\mathrm{I}$ & 0.1295 \\
Threat (T) & $\mathrm{I} / 3$ & $\mathrm{I} / 5$ & $\mathrm{I}$ & 0.1024 \\
\hline
\end{tabular}

Step 4: Evaluation of the strategic alternatives

By taking each influencing factor as the criterion, four strategic alternatives were evaluated, as detailed in supplementary Tables S12 to $\underline{\mathrm{S} 25}$. The weights of the alternatives under each influencing factor were used to form matrix $\omega_{3}$, and then the weight values $\omega_{\text {protocol }}$ of the alternatives were obtained as shown below:

Table 3 Weights of the Influencing Factors

\begin{tabular}{|c|c|c|c|c|}
\hline $\begin{array}{l}\text { Index } \\
\text { Layer }\end{array}$ & Weight & Index Layer & Weight & $\begin{array}{l}\text { Comprehensive } \\
\text { Weight }\left(\omega_{1}\right)\end{array}$ \\
\hline \multirow[t]{4}{*}{$\begin{array}{l}\text { Strength } \\
(\mathrm{S})\end{array}$} & \multirow[t]{4}{*}{0.2409} & $\begin{array}{l}\text { Address the difficult problems in the core technology of high-end medical equipment } \\
\text { through a national system }\end{array}$ & 0.5161 & 0.1243 \\
\hline & & $\begin{array}{l}\text { Some influential industry giants exist in the international high-end medical equipment } \\
\text { market }\end{array}$ & 0.0983 & 0.0237 \\
\hline & & $\begin{array}{l}\text { Trends for the integration of industry and medicine are significant, with large } \\
\text { hospitals cooperating with enterprises to carry out clinical verifications and scientific } \\
\text { research }\end{array}$ & 0.227 & 0.0547 \\
\hline & & $\begin{array}{l}\text { The main investors in the high-end medical equipment industry are more diversified, } \\
\text { and many large private enterprises are involved }\end{array}$ & 0.1586 & 0.0382 \\
\hline \multirow[t]{4}{*}{$\begin{array}{l}\text { Weakness } \\
\text { (W) }\end{array}$} & \multirow[t]{4}{*}{0.5272} & $\begin{array}{l}\text { The domestic high-end medical equipment industry started late, and the domestic } \\
\text { market was monopolized by multinational companies }\end{array}$ & 0.5263 & 0.2775 \\
\hline & & $\begin{array}{l}\text { There is shortage of core technology and components for high-end medical } \\
\text { equipment }\end{array}$ & 0.2217 & 0.1169 \\
\hline & & $\begin{array}{l}\text { The innovation abilities of the enterprises themselves are weak, and joint innovations } \\
\text { among different subjects are insufficient }\end{array}$ & 0.156 & 0.0822 \\
\hline & & $\begin{array}{l}\text { The transformation rates of science and technology achievements in scientific } \\
\text { research institutes during the 14th Five-Year Plan is low }\end{array}$ & 0.096 & 0.0506 \\
\hline \multirow{2}{*}{$\begin{array}{l}\text { Opportunity } \\
\text { (O) }\end{array}$} & \multirow[t]{2}{*}{0.1295} & National policy support for the high-end medical equipment industry & 0.6667 & 0.0863 \\
\hline & & $\begin{array}{l}\text { The government's 14th Five-Year plan for science and technology will lay out the } \\
\text { major fields of medical equipment }\end{array}$ & 0.3333 & 0.0432 \\
\hline \multirow[t]{4}{*}{ Threat $(\mathrm{T})$} & \multirow[t]{4}{*}{0.1024} & $\begin{array}{l}\text { Under the background of trade friction, the research and development abilities of } \\
\text { enterprises facing diversified markets are weak }\end{array}$ & 0.192 & 0.0197 \\
\hline & & Lengthy registration and review cycles for innovative high-end medical equipment & 0.6127 & 0.0627 \\
\hline & & $\begin{array}{l}\text { The lack of supervision of medical equipment after entering the market is prone to } \\
\text { adverse events }\end{array}$ & 0.1077 & 0.0110 \\
\hline & & $\begin{array}{l}\text { Government centralized procurements are restricted by the dealer monopolies in } \\
\text { the sales channels and shortages in the domestic medical equipment market }\end{array}$ & 0.0876 & 0.0090 \\
\hline
\end{tabular}


Table 4 Unweighted Super-Matrix

\begin{tabular}{|c|c|c|c|c|c|c|c|c|c|c|c|c|c|c|}
\hline W & SI & S2 & S3 & S4 & WI & W2 & W3 & W4 & OI & 02 & TI & T2 & T3 & T4 \\
\hline SI & I & & 0.3333 & & & & & & & & & & & \\
\hline S2 & & I & & & & & & & & & & & & \\
\hline S3 & & & 1 & & & & & & & 0.3333 & & & & \\
\hline S4 & & & & I & & & & & & & & & & \\
\hline WI & & & & & I & 0.4554 & & & & & 0.25 & & & \\
\hline W2 & & & & & & I & & & & & & & & \\
\hline W3 & & & & & & 0.1409 & 1 & & & & 0.5 & & & \\
\hline W4 & & & & & & 0.2628 & & I & & & & & & \\
\hline OI & 0.5 & & & & & & & & I & 0.6667 & & & & \\
\hline $\mathrm{O} 2$ & 0.5 & & 0.6667 & & & & & & & I & & & & \\
\hline TI & & & & & & & & & & & I & & & \\
\hline T2 & & & & & & 0.1409 & & & & & 0.25 & I & & \\
\hline T3 & & & & & & & & & & & & & I & \\
\hline T4 & & & & & & & & & & & & & & I \\
\hline
\end{tabular}

\begin{tabular}{|c|c|c|c|c|c|c|c|c|c|c|c|c|c|}
\hline 0.4829 & 0.4512 & 0.0833 & 0.1615 & 0.4829 & 0.1377 & 0.0833 & 0.4829 & 0.25 & 0.1615 & 0.4829 & 0.3334 & 0.0833 & 0.2 \\
\hline 0.157 & 0.2609 & 0.0833 & 0.0601 & 0.157 & 0.4486 & 0.0833 & 0.157 & 0.25 & 0.0601 & 0.157 & 0.3334 & 0.0833 & 0.4 \\
\hline 0.272 & 0.1689 & 0.4167 & 0.4906 & 0.272 & 0.1258 & 0.4167 & 0.272 & 0.25 & 0.4906 & 0.272 & 0.1666 & 0.4167 & 0.2 \\
\hline 0.0882 & 0.119 & 0.4167 & 0.2878 & 0.0882 & 0.2879 & 0.4167 & 0.0882 & 0.25 & 0.2878 & 0.0882 & 0.1666 & 0.4167 & 0.2 \\
\hline
\end{tabular}

]

$$
\omega_{\text {protocol }}=\left[\begin{array}{c}
S O \\
S T \\
W O \\
W T
\end{array}\right]=\omega_{3} . \omega_{\text {factor }}=\left[\begin{array}{l}
0.2962 \\
0.2063 \\
0.3308 \\
0.2527
\end{array}\right]
$$

From the weight values of the strategic alternatives, it was determined that the WO strategy mode was the best strategy mode for the development of China's high-end medical equipment industry. The WO strategy includes speeding up the construction and improvements of technological innovation systems that are enterprisedominated, market-oriented, and involve joint industryuniversity research., as well as increasing the financial support for R\&D and industrialization. In addition, strong support by the government through appropriate policies and measures concerning taxes, medical insurance, talent, and land usage is the key to the development of China's high-end medical equipment industry under the WO strategy.

\section{Conclusions and Discussion}

China's anti-epidemic plan has achieved remarkable results. As a large manufacturing country, China has made efforts to supply basic medical materials and produce high-end medical equipment.

In addition, with the regular epidemic prevention and control, China's high-end medical equipment industry will have good development opportunities. Assuming that the state gives continuous attention to scientific research in future, the key problems will be resolved under a new national system. Furthermore, with the active support of various policies, guaranteed capital investment, and the efforts of enterprises to carry out independent $R \& D$, China's domestic medical device industry is expected to have a promising future in terms of becoming an independent and autonomous high-end industry.

In other words, for China's high-end medical equipment industry to achieve independent innovation and control of the entire industry chain, development cannot 
be rushed. Breakthroughs will be achieved by strengthening the technological innovation abilities of SMEs, and by gradually conquering and mastering the core technology. Therefore, full attention should be given to the advantages of a new national system and the current super large-scale market, while adhering to the decisive role of the market in the allocation of resources. Domestic enterprises should play a leading role, and clinical demands used as guidance, to improve the organizational mechanisms for medical equipment innovations and enhance the ability of both the leading enterprises and the SMEs in technological innovation. In addition, cooperation between the fields of medicine and industry should be further strengthened and international cooperation should be enhanced. Finally, the applications of AI, $5 \mathrm{G}$, and other new technologies should be priorities in the near future. ${ }^{7}$

\section{Ethical Approval of the Institutional Review Board Statement}

The study was conducted according to the guidelines of the Declaration of Helsinki, and approved by the Ethics Committee of the China Three Gorges Corporation, the PostDoctoral Research Station; The Institute for the History of Natural Sciences, the Chinese Academy of Sciences; the Chinese Academy of Sciences Key Laboratory of Cryogenics, the Technical Institute of Physics and Chemistry, PRC; the Beijing Key Lab of CryoBiomedical Engineering, PRC; the School of Future Technology, and the University of Chinese Academy of Sciences, PRC.

\section{Author Contributions}

All authors made a significant contribution to the work reported, whether in the conception, study design, execution, acquisition of data, analysis and interpretation, or in all these areas; took part in drafting, revising, or critically reviewing the article; gave final approval of the version to be published; have agreed on the journal to which the article has been submitted, and agree to be accountable for all aspects of the work.

\section{Funding}

This research is supported by the National Key R\&D Program of China (2018YFC1705106), the National Natural Science Foundation of China (No. 51890893), and the Youth Innovation Promotion Association of the Chinese Academy of Sciences (No. Y722011).

\section{Disclosure}

The authors report no conflicts of interest for this work.

\section{References}

1. Yanan L. [China Medical Equipment Green Book: The Market Scale Reached 800 Billion Yuan by the End of 2019]. ChinaNews 2020 Dec 9. Available from: https://www.chinanews.com/jk/2020/09-12/ 9289630.shtml. Accessed July 12, 2021. Chinese.

2. China Society for Drug Regulation. China Medical Device Industry Development Report. Social Sciences Academic Press; 2020.

3. Xing C, Zhang R. COVID-19 in China: responses, Challenges and Implications for the Health System. Healthcare. 2021;9(1):82. doi:10.3390/healthcare 9010082

4. Sun Z, Yang B, Zhang R, Cheng X. Influencing Factors of Understanding COVID-19 Risks and Coping Behaviors among the Elderly Population. Int $J$ Environ Res Public Health. 2020;17 (16):5889. doi:10.3390/ijerph17165889

5. Wei X. The United States' containment of China's science and technology is intensifying, and the strengthening of weak links of medical equipment must be accelerated China's Informatization. iCHINA. 2020;(5):27-28.

6. I Y, M D. Using the analytic network process (ANP) in a SWOT analysis - a case study for a textile firm. Inf Sci (Ny). 2007;177 (16):3364-3382. doi:10.1016/j.ins.2007.01.001

7. [No authors listed]. [The second summit forum on innovation and development of medical equipment was held in Beijing]. [Instrument Standardization Metrol]. 2020;5:15-16. Chinese.

8. Yanqing L, Qiang Z. President of United Imaging: high-end medical equipment enters the era of "localization". China Econ Weekly. 2014;000(034):42-45.

9. Gang L, Ping R. Build an innovative country, and create a national brand - Zhangjiang National Innovation Demonstration Zone creates a global impact of high-end medical devices. Sci Technol Industry Parks. 2015;172(12):128-131.

10. Gai B, Qu L, Zhou K. [To see the shortcomings of high-end medical equipment under the "magnifying glass" of the epidemic: weak technology, few reserves, low production capacity and no use]. CNHealthcare; 2020. Available from: healthcare.com/article/20200907/ content-541917.html. Accessed July 12, 2021. Chinese.

11. China association of medical equipment. Notice on the Recommendation of Urgently Needed Medical Equipment for COVID-19 Outbreak Control (5th batch). Available from: http:// www.yxzb.org.cn/index.php? $\mathrm{m}=$ home\& $\mathrm{c}=$ View $\& \mathrm{a}=$ index \&aid $=$ 4242020. Accessed June 26, 2021.

12. Zhenliang L, Jing H, Yanghui S, Jiangkang H. Analysis of basic research investment of domestic and foreign enterprises and its Enlightenment to Guangdong. Sci Technol Manage Res. 2020;40 (02):189-195.

13. Shilin Z. Challenges and suggestions for China to be in the front rank of innovative countries. Today Sci Technol. 2020;(12):31-33.

14. Jianqi Z, Taishan G, Shuping M. Promoting joint innovation of China's high-end medical equipment industry chain. Research and Investigation Report, No. 254 (total No. 5998). Available from: http:// www.drc.gov.cn/DocView.aspx? chnid=386\&leafid=1339\&docid= 29019712020. Accessed June 26, 2021. 
15. Hui S. The transformation rate of biomedical achievements is only $5 \%$, and the transformation of pharmaceutical innovation achievements needs to be strengthened. Econ Daily China Econ Net. 2020.

16. Gongyao Z, Jun L. Basic Course of $3 D$ Printing. People's Oriental Publishing House; 2016.

17. Xinhua News Agency. Suggestions of the CPC Central Committee on formulating the 14th Five-Year Plan for national economic and social development and the long term goals for the year 2035; 2020.

18. The Ministry of Finance of the People's Republic of China issued the Notice on sorting out and standardizing policies related to a number of administrative fees; 2017.

19. Fan X. Registration of high-end medical devices takes a long time, and it is common to take two or three years to complete the registration. Econ Inform Daily. 2017.

20. Beibei C, Yongli T, Hao T, Pengfei W. Current situation and improvement of monitoring of medical device adverse events in hospital. Chin J Med Devices. 2020;33(19):49-51.

21. Yi Wen XY, Chen X. The founding meeting of China medical device industry technology innovation strategic alliance was held in Beijing. China Med Device Inform. 2009;015(006):69-71.

22. Biological Industry Development Bureau of Chengdu hi tech Zone. Chengdu sets up technology innovation strategic alliance of medical device industry. Today Sci Technol. 2010;7:20.
23. Qiu X, Qian B, Yao S. Construction and effectiveness of technological innovation strategic alliance of medical device industry in Zhejiang Province. Med Equipment. 2016.

24. Shi T. The establishment and effectiveness of Shanghai medical device industry technology innovation strategic alliance. Technol Innov Product. 2016;000(005):12-15.

25. Jichuan G. High end medical equipment is frequently supported by policies, and 18 enterprises have landed on the science and technology innovation board. Securities Daily. 2020.

26. Jun M, Dongming Y, Shuping M, Jianqi Z; High-end medical equipment innovation research" research group of Enterprise Research Institute of Development Research Center of the State Council. Six problems to be solved in the development of China's high-end medical industry. Sohu News. 2020

27. Lu W, Zheng M, Xiaoyang X, Yali L. Research Report on development status and countermeasures of combination of medicine and industry in China. J Clin Med Practice. 2019;23(05):1-6.

28. Songsheng Z, Lei D, Wei W, Bin L, Xiaoling W. Cultivating innovative medical engineering talents by "medical and industrial integration”. Res Exploration Lab. 2016;35(12):212-214.
Risk Management and Healthcare Policy

\section{Publish your work in this journal}

Risk Management and Healthcare Policy is an international, peerreviewed, open access journal focusing on all aspects of public health, policy, and preventative measures to promote good health and improve morbidity and mortality in the population. The journal welcomes submitted papers covering original research, basic science, clinical \& epidemiological studies, reviews and evaluations,
Dovepress

guidelines, expert opinion and commentary, case reports and extended reports. The manuscript management system is completely online and includes a very quick and fair peer-review system, which is all easy to use. Visit http://www.dovepress.com/testimonials.php to read real quotes from published authors. 